\title{
Concurrent and Longitudinal Correlates of Preschool Peer Sociometrics: Comparing Rating Scale and Nomination Measures
}

\author{
SHERYL L. Olson \\ University of Michigan \\ KAREN LIFGREN \\ University of Maine
}

\begin{abstract}
Nomination and rating scale measures of preschool sociometric status were compared with respect to their patterns of concurrent and longitudinal developmental correlates. The study was undertaken to help fill a void in the empirical literature on young children's peer adjustment. Subjects were 79 4-5 year-old children, currently enrolled in preschool classes. In addition to the sociometric interviews, diverse measures of children's social and cognitive competence were administered concurrently, and longitudinally one year later. These measures included teacher ratings of peer acceptance and behavior problems, and performance measures of social problemsolving ability, impulse control, and vocabulary competence. As expected, the reliability of the rating scale technique was superior to that of the nomination measures. Furthermore, all three sociometric measures had modest but meaningful patterns of concurrent and longitudinal correlates. However, the negative nomination measure was distinguished from the others by its consistent association with measures of impulsivity, and its predictive link with aggressive social problem solving. Therefore, negative peer nomination measures supply unique information about children's social functioning that should be represented in studies of children at risk for social maladjustment.
\end{abstract}

During the past decade, there have been numerous research studies on the measurement of social status in school-age children. This trend was sparked in part by evidence linking negative childhood peer status with later interpersonal difficulties (Cowen, Pederson, Babigian, Izzo, \& Trost, 1973). However, relatively little attention has been given to the early detection and prevention of peer-

Portions of the present study were presented at the biennial meeting of the Society for Research in Child Development, Detroit, MI., April, 1983. The authors are indebted to the teachers, admin. istrative staffs, and children of the Child Study Center. Hilltop Daycare Center, and Penquis Head Start for their help with the present project. Thanks are also due to Jane Parks, Janelle Johnson, Betsy Hoza, Nancy Benigno, and Edward Barrett for assistance with data collection.

Correspondence and requests for reprints should be sent to: S.L. Olson, Department of Psychology, University of Michigan, 580 Union Drive, Ann Arbor, MI 48109-1346. 
related social maladjustment (Hymel, 1983; Ladd \& Mars, 1986). Although several different approaches to the measurement of social status in preschool children have been developed, empirical comparisons of these measures have been infrequent. Furthermore, little is known about the longitudinal correlates of preschool-age peer sociometric measures. Clearly, there is a need for further research on the measurement of peer status in early childhood.

Two different sociometric measures have been most frequently used to assess social status in preschool children: nominations of liked and disliked classmates (McCandless \& Marshall, 1957), and ratings of likeability assessed for all children in the respondent's social reference group (Asher, Singleton, Tinsley, \& Hymel, 1979). The nomination method simply requires each child to name three or more classmates that he or she likes to play with and three or more classmates that he or she does not like to play with. Typically, "acceptance" and "rejection" scores have been computed for each child, based on relative numbers of unweighted nominations in each category (e.g. Gottman, 1977). The rating scale measure (Asher et al., 1979) provides an alternative method of peer sociometric assessment. At the preschool level, children are required to rate each classmate on three-point "scales" by assigning his or her photo to one of three different boxes. The boxes are labelle ' with happy, neutral, and sad faces, respectively, and the child is asked to assign photos to boxes according to how much he or she likes to play with the classmate. Each child's resulting social status score is the average rating received from all classmates. According to Asher et al., the rating scale measure was designed to improve upon method limitations inherent in the nomination technique. However, both alternative measures appear to have unique strengths and weaknesses. Following Hymel (1983), the measures will be briefly compared according to the following criteria: ease of administration, testretest reliability, concurrent validity, utility in generating extreme groups of "at risk" children, and predictive validity. In addition, a somewhat newer issue concerning ethical implications of the measures is briefly discussed.

The rating scale and nomination measures are both relatively easy to administer, requiring only short (10-15 min) interviews with each child. Other sociometric techniques have been developed to assess preschoolers' perceptions of all classmates, such as the paired comparison method (Cohen \& Van Tassel, 1978), but require long administration times.

However, the rating scale and nomination methods do not appear to be equally reliable at the preschool level. Studies of the stability of preschool-age nomination scores have yielded variable reliability coefficients, with moderate average test-retest correlations (Hartup, Glazer, \& Charlesworth, 1967; McCandless \& Marshall, 1957; Moore \& Updegraff, 1964). Reliability coefficients also appear to vary according to the type of nomination score, with lowest test-retest correlations for negative scores (Hartup et al., 1967). The rating measure differs from the nomination measures in that every child in the class is rated by all classmates. Proponents of the measure have argued that this change should result in improved reliability, by increasing the total number of data points for each 
child (Hymel, 1983), and by reducing the vulnerability of the sociometric scores to biases based on friendship (Asher \& Hymel, 1981). Indeed, Asher et al. (1979) found that in two different classes of preschool children, the rating score did have higher average test-retest reliability $(.74-.81)$ over a 4-week interval than the positive nomination (.38-.56) or negative nomination (.42) scores. Thus, a major advantage of the Asher scale appears to be superior relative stability at the preschool level. However, further comparative reserach is needed before this generalization can be fully supported, particularly since small sample sizes were used in the Asher study.

How do the different measures fare with respect to patterns of concurrent validity? Despite their often marginal reliability, nomination scores have been consistently correlated with independent measures of preschool children's socialadaptive functioning, including observational measures of peer interaction, teacher ratings of social adjustment, and even measures of social-cognitive maturity (Hymel, 1983). Due to the newness of the measure, concurrent validity studies of the Asher scale have been less frequent. In one report, Asher scale preschool sociometric scores showed modest but predictable patterns of convergence with teacher ratings of maladjustment on the Behar questionnaire (Rubin \& Clark, 1983). However, relatively few investigators have compared concurrent validity coefficients between preschool rating scale and nomination sociometrics. Some preliminary findings (summarized in Hymel, 1983) suggest that rating scale measures are better predictors of social behavior than nomination measures, but further investigation is needed before firm conclusions can be drawn.

A related issue concerns the relatively utility of the two methods in generating meaningful classifications of "at risk" children. A potential disadvantage of the rating scale measure is that it does not permit distinctions between rejected (actively disliked) and neglected (ignored) children. Both types of children would probably receive low rating scores, but could be easily differentiated by the nomination measures. This distinction is an important one, because rejected and neglected children appear to represent different dimensions of social maladjustment (Goldman, Corsini, \& deUrioste, 1980). For example, peer rejection has been consistently associated with aggressive, impulsive, and disruptive behavioral tendencies in school-age children (e.g., Dodge, Coie, \& Brakke, 1982; Milich \& Landau, 1982) but this has not generally been the case for measures of peer popularity.

As Hymel (1983) has noted, very little information is available concerning the predictive validity of any preschool sociometric measure. This "void" in the research literature is ironic, because peer sociometric measures are often used to target children at elevated risk for social deviance. In one study (Rubin \& Daniels-Bierness, 1983) kindergartners' ratings scores were found to have modest but interpretable predictive correlations with measures of social competence assessed one year later. However, further examination of this important issue is clearly needed. 
Finally, the use of procedures which require children to make negative sociometric choices has been questioned on ethical grounds (Asher, 1983). For example, some have questioned whether the process of nominating disliked peers may further impair these children's reputations, due to ensuing "gossip" about the interview procedures, or to a crystallization of negative attitudes about the disliked peers on behalf of the respondents. Both sociometric techniques are vulnerable to these objections, since they involve the use of negative choices in the interview situation.

The purpose of the present study was to compare preschool rating scale and nomination sociometrics with respect to their patterns of concurrent and longitudinal correlates. Developmental domains critical to preschool children's social adjustment were assessed using multiple measures, and correlated with the different indexes of social status. Teachers contributed ratings of behavioral maladjustment and peer acceptance. A widely used test of social problem-solving ability was also included, because this social-cognitive skill dimension has been established as a reliable correlate of social adjustment in young cnildren (Krasnor and Rubin, 1981). In order to examine individual differences in self-control capabilities, several different performance tests of impulsivity were administered to each child. Finally, a measure of vocabulary ability was included as well, because cognitive/linguistic competence is a nonsocial individual difference dimension with important implications for children's social adjustment (Hops, 1983). All measures were readministered one year later, so that longitudinal correlates of different sociometric measures could be examined.

\section{METHOD}

\section{Subjects}

Subjects were 79 white $4-5$-year-old children ( 47 boys, 32 girls) currently enrolled in university and community preschools. Their mean chronological age at time of assessment was 56 months ( $S D=10$ months, range $=48-68$ months). Familial social class ranged from lower- to upper-middle. Forty children from predominantly middle-income families attended classes in a university preschool setting, and thirty-nine children from exclusively low-income families attended Head Start classes in the greater Bangor area. Written parental consent and verbal child assent were obtained for all assessment procedures.

Follow-up assessments were conducted one year later on a sample of 56 children ( 34 boys, 22 girls). Most sample attrition was due to familial relocation.

\section{Instruments}

Peer Sociometric Measures. Two sociometric measures were used to assess individual differences in peer acceptance: the rating scale developed by Asher et 
al. (1979) and nominations of most versus least preferred playmates (McCandless \& Marshall, 1957). Each child was interviewed individually by a female graduate student. First, using the technique detailed by McCandless and Marshall, the child was shown a poster board on which photographs of all children in the class were mounted. Children were asked to identify themselves in the array, and to name each classmate. They were next asked to point to the pictures of three children they most liked to play with, then three children they least liked to play with at preschool. The rating scale task was explained next, using instructions and training exercises described in Asher et al. (1979). Children were then asked to assign pictures of each classmate to one of three boxes, which depicted either a happy face ("children you like to play with alot"), a neutral face ("children you "kinda' like to play with"), or a sad face ("children you don't like to play with"). Resulting rating and nomination scores were divided by the number of raters in each class (to correct for differences in class sizes) and transformed into standard scores. The following summary variables (Z-scores) were obtained for each child: number of positive nominations, number of negative nominations, and average rating on the Asher scale.

Performance Tests of Self-Control. Three different performance measures of self-control were individually administered to each child. 1) The Kansas Reflection-Impulsivity Scale for Preschoolers (KRISP; Wright, 1971) is a match-tosample test of cognitive impulsivity that yields mean scores for number of errors and for latency to first response. After Salkind and Wright (1977), a total cognitive impulsivity score was computed by subtracting the reaction time from the error score. 2) Draw-a-Line-Slowly/Walk-a-Line-Slowly (DALS/WALS; Maccoby, Dowley, Hagen, \& Degerman, 1965) is a measure of the ability to inhibit fine and gross motor movements in response to situational demands. The child is asked to draw and walk straight lines at regular speed (two trials) and then "as slowly as possible" (two trials), yielding inhibition scores (average slow minus average regular times) for each child. 3) Finally, a delay of gratification task (Arend, Gove, \& Sroufe, 1979) was administered. In this task the examiner "discovers" a small wrapped gift and informs the child that he or she may have it "later." A 2-min cover task and 90-second delay period is then carried out, during which E records any attempts to open the gift prematurely. Each child's delay score is the time (in seconds) which elapses before the gift is taken.

Social Problem-Solving. The Preschool Interpersonal Problem-Solving Test (PIPS; Shure \& Spivack, 1974) was administered to each child. In this test, the child is presented with a series of hypothetical social problem situations involving same-sex age peers (one child has a toy that another child wants to play with) and mother-child interaction (a child accidentally damages a household object or maternal possession), and is asked to name as many different problem solutions as possible. Children's responses were assigned to the categories described in the 
PIPS manual. All protocols were independently scored by two raters, whose levels of agreement ranged from 91-100\% for the different categories. When inter-scorer disagreements occurred, final decisions were made by the senior author. The following summary scores were computed for each child: total number of relevant solutions, proportionate number of irrelevant story solutions ("relevance ratio"), and proportionate number of forceful-agressive solutions ("force ratio").

Vocabulary Test. The Peabody Picture Vocabulary Test-Revised (PPVT-R; Dunn and Dunn, 1981) was administered, in order to obtain an index of each child's level of linguistic maturity.

Teacher Ratings of Social Adjustment. Teachers completed a 42-item preschool-appropriate adaptation of Quay and Peterson's (1975) Behavior Problem Checklist (O'Donnell \& Van Tuinan, 1979). This questionnaire has two broadfactor scale dimensions: Aggression (hostile, destructive, disruptive, uncooperative, and hyperactive behavior) and Anxiety (general fearfulness, social withdrawal, lack of self-confidence). Teachers also rated each child's level of social competence using the Preschool Competence Questionnaire (Olson, 1984). This questionnaire consists of 504 -point scales on which specific areas of competence are rated according to the following scale descriptors: " 0 " = behavior that never or rarely occurs, " 1 " = behavior that occurs once in awhile, " 2 "" $=$ behavior that occurs more often than not, and " 3 " = behavior that occurs very frequently. The Positive Peer Interaction scale was extracted for use in the present study. This scale consists of 7 items which index the relative frequency of active, friendly peer initiations and responsiveness (e.g., initiates play with peers; sought out by peers for play; responds positively to friendly peer initiations).

\section{Procedures}

Tests of children's self-control, vocabulary, and social problem-solving abilities were administered during three separate sessions. Tests were administered individually on different days within a 3-week time period. Prior to testing, each child had two sessions of within-classroom play contact with the examiner, in order to facilitate rapport. Examiners were 3 graduate students ( 2 female, 1 male) and 3 undergraduate students ( 2 female, 1 male) who received one semester of supervised training with the test materials prior to the onset of the study. The order in which the tests were administered was counterbalanced between subjects.

Follow-up assessments of self-control, social problem-solving, and vocabulary ability were conducted one year later $(n=56)$, using measures and procedures described above. Means and standard deviations for all measures, times 1 and 2, are shown in Table 1. All measures were transformed into standard (z) scores before entry into data analyses. 
TABLE 1

Means and Standard Doviations for Time-1 and Time-2 Measures

\begin{tabular}{|c|c|c|c|c|}
\hline & \multicolumn{2}{|c|}{ Time 1} & \multicolumn{2}{|c|}{ Time 2} \\
\hline & $M$ & $S D$ & $M$ & so \\
\hline \multicolumn{5}{|l|}{ Test Variables } \\
\hline $\begin{array}{l}\text { Kansas Reflection-Impulsivity } \\
\text { Scale for Preschoolers }\end{array}$ & .47 & .35 & .24 & .18 \\
\hline $\begin{array}{l}\text { Peabody Picture Vocabulary } \\
\text { Test }\end{array}$ & 103.89 & 16.25 & 106.17 & 18.98 \\
\hline Motor Inhibition-Draw & 7.36 & 8.01 & 15.76 & 15.24 \\
\hline Motor Inhibition-Walk & 5.19 & 4.94 & 10.02 & 11.27 \\
\hline Delay of Gratification & 65.77 & 35.22 & 61.98 & 35.99 \\
\hline $\begin{array}{l}\text { Preschool Interpersonal Prob- } \\
\text { lem-Solving-Total }\end{array}$ & 6.85 & 2.96 & 9.25 & 3.17 \\
\hline $\begin{array}{l}\text { Preschool Interpersonal Prob- } \\
\text { lem-Solving-Force }\end{array}$ & .14 & .19 & .13 & .15 \\
\hline \multicolumn{5}{|l|}{ Teacher Rating Scales } \\
\hline $\begin{array}{l}\text { Aggression (Behavior Prob- } \\
\text { lem Checklist) }\end{array}$ & 5.23 & 5.52 & 4.82 & 4.83 \\
\hline $\begin{array}{l}\text { Anxiety-Withdrawal (Behavior } \\
\text { Problem Checklist) }\end{array}$ & 3.95 & 3.80 & 3.25 & 3.34 \\
\hline $\begin{array}{l}\text { Peer Interaction (Preschool } \\
\text { Competence Questionnaire) }\end{array}$ & 12.01 & 4.76 & 15.92 & 4.12 \\
\hline \multicolumn{5}{|l|}{ Peer Sociometric Variables } \\
\hline Asher Rating & 2.25 & .38 & - & - \\
\hline Positive Nominations & .23 & .15 & - & - \\
\hline Negative Nominations & .21 & .17 & - & 一 \\
\hline
\end{tabular}

\section{RESULTS}

\section{Correlations Between Peer Sociometric Measures}

Positive and negative nomination scores were not significantly intercorrelated ( $r$ $=.03$ ). However, the Asher rating scale score was moderately highly correlated with both nomination measures, in the expected directions $(r=.48$ with positive nominations, $r=-.43$ with negative nominations; both $p s<.001$ ).

\section{Reliability}

Three-week test-retest reliability trials were conducted using three preschool classes $(n=34)$. Reliability coefficients for each sociometric measure were as follows: positive nominations, $r=.52(p<.01)$; negative nominations, $r=.48$ $(p<.01)$; and rating scores, $\mathrm{r}=.81(p<.001)$. This pattern of findings is highly consistent with the reliability comparisons reported by Asher et al. (1979). 
TABLE 2

Concurrent Correlates of Preschool Sociometric Ratings and Nominations

\begin{tabular}{|c|c|c|c|}
\hline \multirow{3}{*}{$\begin{array}{l}\text { Performance Measures } \\
\text { Kansas Reflection-Impulsivity } \\
\text { Scale for Preschoolers }\end{array}$} & \multicolumn{3}{|c|}{ Sociometric Measures } \\
\hline & $\begin{array}{c}\text { Rating } \\
\text { Score }\end{array}$ & $\begin{array}{c}\text { Positive } \\
\text { Nomination }\end{array}$ & $\begin{array}{c}\text { Negative } \\
\text { Nomination }\end{array}$ \\
\hline & .08 & .17 & $.40 * *$ \\
\hline Delay of gratification & .14 & -.19 & $-.30 *$ \\
\hline Motor inhibition-Walk & .09 & .07 & .13 \\
\hline Motor inhibition-Draw & .17 & .21 & .12 \\
\hline Peabody vocabulary & .09 & .18 & $-.26 *$ \\
\hline $\begin{array}{l}\text { Preschool Interpersonal } \\
\text { Problem-Solving: Total so- } \\
\text { lutions }\end{array}$ & .15 & $.27^{*}$ & .12 \\
\hline $\begin{array}{l}\text { Preschool Interpersonal } \\
\text { Problem-Solving: Force } \\
\text { ratio }\end{array}$ & .00 & .07 & .04 \\
\hline \multicolumn{4}{|l|}{ Teacher Rating Scales } \\
\hline Positive Peer Interaction & $.23^{*}$ & $.31 * *$ & $-.23^{*}$ \\
\hline Aggression & $-.27^{*}$ & .05 & $.25^{*}$ \\
\hline Anxiety & -.07 & .11 & .15 \\
\hline
\end{tabular}

Note. All tests one-tailed

$* p<.05, * * p<.01$.

\section{Concurrent Correlates}

Concurrent correlates of the different sociometric measures are shown in Table 2. The rating scale sociometric had no significant correlates in performance measures of children's social and cognitive competence. However, rating scale scores were modestly positively correlated with teachers' ratings of peer acceptance, and modestly negatively correlated with ratings of aggression. Consistent with previous research (Goldman et al., 1981), positive and negative nomination scores had different patterns of developmental correlates. Positive nominations converged meaningfully with children's total social problem-solving scores on the PIPS test, and with teachers' ratings of peer acceptance. The negative nomination measure had the greatest number and variety of significant correlates. Negative nomination scores showed meaningful convergences with teachers' assessments of peer acceptance and aggression, and were modestly predictive of low scores on the Peabody vocabulary test. Unlike the other measures, negative nominations were associated with impulsive performance on two different measures of self-control: the KRISP test of cognitive style, and the delay of gratification task. It is noteworthy that the rating scale and negative nomination measures showed extremely similar patterns of correlation with teacher rating scales, but 
very different patterns of correlation with specific measures of developmental competence.

\section{Longitudinal Correlates}

Correlations between preschool sociometric scores and 1-year follow-up measures of children's social and cognitive competence are shown in Table 3 . Generally, all three sociometric measures predicted relevant aspects of children's later social and cognitive competence. Rating scale scores predicted two different performance measures of children's later competence: ability to inhibit fine motor movement in the inhibition task, and ability to generate relevant solutions to hypothetical social problem situations on the PIPS test. Positive nomination scores also predicted children's later motor inhibition ability, as well as competent performance on the Peabody vocabulary test. All three sociometric measures were modestly predictive of later teacher evaluations of children's peer acceptance; negative nomination scores were also predictive of later anxious-withdrawn behavioral tendencies, as rated by teachers. Consistent with the reported pattern of concurrent relationships, negative nomination scores showed a distinctive pattern of longitudinal correlates. Negative nomination scores were predictive of nearly every follow-up measure of impulsivity, in the expected directions. Furthermore, although negative nomination scores did not predict overall

TABLE 3

Longitudinal Corrolates of Preschool Sociometric Ratings and Nominations

\begin{tabular}{|c|c|c|c|}
\hline \multirow[b]{2}{*}{$\begin{array}{l}\text { Performance Measures-Time } 2 \\
\text { Kansas Reflection-Impulsivity } \\
\text { Scale for Preschoolers }\end{array}$} & \multicolumn{3}{|c|}{ Sociometric Measures (Time 1) } \\
\hline & $\begin{array}{l}\text { Rating } \\
\text { Score } \\
-.06\end{array}$ & $\begin{array}{l}\text { Positive } \\
\text { Nomination } \\
-.23\end{array}$ & $\begin{array}{c}\text { Negative } \\
\text { Nomination } \\
.35^{*}\end{array}$ \\
\hline Delay of gratification & .20 & -.12 & $-.48 * *$ \\
\hline Motor inhibition-Walk & .05 & $.29 *$ & -.22 \\
\hline Motor inhibition-Draw & $.30^{*}$ & -.09 & $-.28 *$ \\
\hline Peabody vocabulary & .05 & $.32 *$ & -.18 \\
\hline $\begin{array}{l}\text { Preschool Interpersonal Prob- } \\
\text { lem-Solving: Total solutions }\end{array}$ & $.30^{*}$ & .13 & .04 \\
\hline $\begin{array}{l}\text { Preschool Interpersonal Prob- } \\
\text { lem-Solving: Force ratio }\end{array}$ & -.23 & .11 & $.39 *$ \\
\hline \multirow{3}{*}{$\begin{array}{l}\text { Teacher Rating Scales-Time } 2 \\
\text { Positive Peer Interaction } \\
\text { Aggression } \\
\text { Anxiety }\end{array}$} & & & \\
\hline & .04 & .04 & .09 \\
\hline & -.16 & -.12 & $.28^{*}$ \\
\hline
\end{tabular}

Note. All tests one-tailed

$* p<.05,{ }^{*} p<.01$. 
social problem-solving ability on the PIPS test, they were significantly correlated with later preference for forceful-aggressive solutions.

\section{DISCUSSION}

Empirical comparisons of alternative preschool peer sociometric measures have been rare, even though these measures are widely used in child development research. The idea that peer sociometric measures may predict children's later social adjustment underlies some of the current interest in these measures. Ironically, however, there has been almost no research on the longitudinal correlates of preschool sociometric measures. Thus, the goal of the present study was to compare patterns of concurrent and longitudinal correlates associated with two popular measures of sociometric status in preschool children: the traditional nomination technique, and the newer rating scale measure.

Consistent with earlier findings reported by Asher et al. (1979), the test-retest reliability of the rating scale sociometric measure was superior to that of the nomination measures. Thus, our combined findings lend support to the conclusion that the Asher scale has greater stability than nomination measures at the preschool level. However, it is possible that a bias against the nomination measure may have been introduced into the study, by always presenting it before the rating task. That is, presenting the nomination task first may serve to "prime" the children for the rating task. This hypothesis is worthy of further study, and could be easily examined by counterbalancing the order in which the respective tasks are presented.

When global ratings of peer acceptance and psychopathology were used as validational criteria, all three measures showed similar patterns of concurrent and longitudinal correlates. However, when more precise measures of children's developmental functioning were examined, rating scale and nomination measures showed different patterns of correlates. Although the Asher scale had no significant concurrent developmental correlates aside from global rating measures, it did predict children's fine motor inhibition and overall social problemsolving ability 1 year later. The positive nomination score was also associated with children's overall social problem-solving ability, and with measures of gross motor inhibition ability and vocabulary competence. In contrast, the negative nomination score was consistently correlated with measures of impulsivity, particularly high error scores combined with low reaction times on the KRISP test, and inability to wait for a reward. Furthermore, whereas the other measures of peer status were associated with overall ability to generate solutions to hypothetical social problem situations, the negative nomination score predicted later use of forceful-aggressive solutions.

In conclusion, all three peer sociometric measures had meaningful concurrent and longitudinal correlates. However, consistent with previous research (cf. Coie, Dodge, \& Coppotelli, 1982; Goldman et al., 1980), the pattern of these 
correlations shows that measures of peer rejection and popularity are tapping different dimensions of young children's social functioning. Our findings extend the association between negative peer status and low impulse control to the preschool level, and show that negative peer status is predictive of continuing impulsivity. Furthermore, our findings suggest that negative peer status is predictive of a later tendency to use forceful-aggressive solutions in social problemsolving. This is a meaningful association, because Richard and Dodge (1981) have shown that school-age boys identified as aggressive by their peers tend to choose coercive-aggressive solutions to hypothetical social problem-solving situations. Thus, important information may be lost if measures of negative peer status are excluded from studies of children at risk for social maladjustment. However, ethical reservations concerning the use of negative sociometric choices remain an important issue. Although this complex issue is far from settled (especially with very young children), it would be helpful to have valid teacher report measures of children's negative peer status, and/or alternative peer sociometric measures of "rejected" status which do not require children to make negative choices.

\section{REFERENCES}

Arend, R., Gove, R.L., \& Sroufe, L.A. (1979). Continuity of individual adaptation from infancy to kindergarten: A predictive study of ego-resiliency and curiosity in preschoolers. Child Development, 50, 950-959.

Asher, S.R. (1983). Social competence and peer status: Recent advances and further directions. Child Development, 54, 1427-1434.

Asher, S.R., \& Hymel, S. (1981). Children's social competence in peer relations: Sociometric and behavioral assessment. In J.D. Wine \& M.D. Smythe (Eds.), Social competence. New York: Guilford Press.

Asher, S.R., Singleton, L.C., Tinsley, B.R., \& Hymel, S. (1979). A reliable sociometric measure for preschool children. Developmental Psychology, 15, 443-444.

Cohen, A.S., \& Van Tassel, E. (1978). A comparison of partial and complete paired comparisons in sociometric measurement of preschool groups. Applied Psychological Measurement, 2. 3140.

Coie, J.D., Dodge, K.A., \& Coppotelli, H. (1982). Dimensions and types of social status. Developmental Psychology, 18, 557-570.

Cowen, E.L., Pederson, A., Babigian, H., Izzo, L.D., \& Trost, M.A. (1973). Long-term follow-up of early detected vulnerable children. Journal of Consulting and Clinical Psychology, 41. $438-446$.

Dodge, K.A., Coie, J., \& Brakke, N. (1982). Behavior patterns of socially rejected and neglected preadolescents: The role of social approach and aggression. Journal of Abnormal Child Psychology, 10, 389-409.

Dunn, L.M., \& Dunn, L. (1981). Peabody Picture Vocabulary Test-Revised. Circle Pines, MN: American Guidance Services.

Goldman, J.A., Corsini, D.A., \& deUrioste, R. (1980). Implications of positive and negative sociometric status for assessing the social compctence of young children. Journal of Applied Developmental Psychology, 1, 209-220.

Gottman, J. (1977). Toward a definition of social isolation in children. Child Development, 48, 513517. 
Hartup, W.W., Glazer, J.A., \& Charlesworth, R. (1967). Peer reinforcement and sociometric status. Child Development, 38, 1017-1024.

Hops, H. (1983). Children's social competence and skill: Current rescarch practices and future directions. Behavior Therapy, 14, 3-18.

Hymel, S. (1983). Preschool children's peer relations: Issues in sociometric assessment. MerrillPalmer Quarterly, 29, 237-259.

Krasnor, L.R., \& Rubin, K. (1981). Assessment of social problem solving in young children. In T. Merluzzi, C. Glass, \& M. Genest (Eds.), Cognitive assessment. New York: Guilford Press.

Ladd, G.W., \& Mars, K.T. (1986). Reliability and validity of preschooler's perceptions of peer behavior. Journal of Clinical Child Psychology, 15, 16-25.

Maccoby, E.E., Dowley, E., Hagen, J.. \& Degerman, R. (1965). Activity level and intellectual functioning in normal preschool children. Child Development, 36, 761-770.

McCandless, B.R., \& Marshall, H.R. (1957). A picture sociometric technique for preschool children and its relation to teacher judgements of friendship. Child Development, 28, 139-148.

Milich, R., \& Landau, S. (1982). Socialization and peer relations in hyperactive children. In K. Gadow \& I. Bialer (Eds.), Advances in learning and behavioral disabilities. (Vol. 1). Greenwich, CT: JAI Press.

Moore, S.G., \& Updegraff, R. (1964). Sociometric status of preschool children related to age, sex, nurturance giving, and dependency. Child Development, 35, 519-524.

O'Donnell, J., \& Van Tuinan, M. (1979). Behavior problems of preschool children: Dimensions and congenital correlates. Journal of Abnormal Child Psychology, 7, 61-75.

Olson, S.L. (1984). Manual for the Preschool Competence Questionnaire. Unpublished manuscript, University of Maine, Orono, ME.

Quay, H.C., \& Peterson, D.R. (1975). Manual for the Behavior Problem Checklist. Unpublished manuscript, University of Miami.

Richard, B.A., \& Dodge, K.A. (1981). Social maladjustment and problem-solving in school-aged children. Journal of Consulting and Clinical Psychology, 50, 226-233.

Rubin, K., \& Clark, M.L. (1983). Preschool teachers' ratings of behavioral problems: Observational, sociometric, and social-cognitive correlates. Journal of Abnormal Child Psychology, $11,273-286$.

Rubin, K., \& Daniels-Bierness, T. (1983). Concurrent and predictive correlates of sociometric status in kindergarten and grade one children. Merrill-Palmer Quarterly, 29, 337-352.

Salkind, N., \& Wright, J. (1977). Reflection-impulsivity and cognitive efficiency: An integrated model. Human Development, 20. 377-387.

Shure, M.B., \& Spivack, G. (1974). Preschool Interpersonal Problem-Solving Test Manual. Philadelphia: Hahnemann Medical School and Hospital.

Wright, J.C. (1971). The Kansas Reflection Impulsivity Scale for Preschoolers. St. Louis, MO: Central Midwestern Regional Educational Laboratory, Inc. 